\title{
Capstone Courses and Major Projects for Enhancing Generation Z Career Readiness Through General Higher-Education Classroom Curriculum
}

\author{
Amanda J. Muhammad \\ Indiana State University \\ Azizi Arrington-Slocum \\ Indiana State University \\ Lisa Hughes \\ Indiana State University
}

The limited literature connecting the design and implementation of capstone and major project courses in general education classrooms using a cross-disciplinary approach requires addressing. This manuscript aims to recognize Gen Z's unique characteristics in comparison to workforce requirements. Additionally, based on the groups' distinguishing traits and needs, a higher education general classroom major project or capstone course was designed. The design's purpose was to provide students with multiple opportunities to access high-impact strategies proven to enhance students' success beyond their major. An interdisciplinary process was developed to meet varying constituents' needs employing a five-phase planning and execution process.

Keywords: capstone courses, major projects, interdisciplinary, generation z, high impact practices

\section{INTRODUCTION}

Capstone courses and major projects' (CCMPs) fundamental goal is to provide an integrative cumulative experience that assesses students' learning and application of course content and prepares them for their chosen profession (Kinzie, 2013; Schermer \& Gray, 2012). In many educational programs where students must provide evidence of abilities for attaining employment, CCMPs are longstanding (NewtonCalvert \& Smith Arthur, 2018). However, discussions about best practices for developing, implementing, and evaluating them have not been fully explored in the literature. Current discussions do not thoroughly examine considerations of specific student populations, industry needs, varied learning environments, or high-impact practices (HIPs; Linder \& Hayes, 2018). CCMPs also require scaffolded academic experiences in preparation for the capstone course's rigor (Kinzie, 2013). Generation Z (Gen Z) students constitute most classrooms from middle school to college (Chicca \& Shellenbarger, 2018; Mitnick, 2021). Instructors, therefore, must not overlook the learning characteristics and needs of Gen $\mathrm{Z}$ students when designing CCMPs, to capture and maintain their interest, which can potentially directly impact and enhance their 
learning. Educators who fail to adapt their methods may miss the opportunity to harness their energy and align the classroom with students' expectations and values.

Additionally, nationally, institutions are pushing the curriculum toward broader implementations of HIPs across all academic areas, including general education courses, due to their impactful nature (Kinzie, 2012; Kuh, Jankowski, Ikenberry, \& Kinzie, 2014). As educators visualize what this may look like, some may be challenged to conceptualize courses such as CCMPs that are real-world and practical into what has been traditionally lecture and research paper based despite the recognized value of HIPs. Thus, appropriate development of CCMPs requires considering best education practices, learners' characteristics, and the components, structures, and benefits of CCMPs.

This paper analyzes and assesses the alignment of CCMPs with Gen Z's particular needs, including the benefits, skills, and knowledge enhancements resulting from implementing CCMPs into the general education classroom environment from an interdisciplinary approach. The authors utilize various recommended strategies, literature reviews, and experiences designing and implementing credit-bearing CCMPs in higher education general classrooms and consider course content, instructional methods, and student outcomes for CCMP design, implementation, and evaluation.

\section{GEN Z}

\section{Gen Z Characteristics}

An interdisciplinary approach to understanding the Gen $\mathrm{Z}$ population helped build this profile and includes those born between 1995 and 2012 (Mitnick, 2021; Mosca, Curtis, \& Savoth, 2019; Nicholas, 2020). This cohort, also known as the iGeneration or $\mathrm{M}^{2}$ (Nicholas, 2020), makes-up nearly a quarter of the U.S. population (Chicca \& Shellenbarger, 2018). These individuals began entering college classrooms around 2013. They will be matriculating through higher education for at least the next decade or approximately 2030. The oldest of this group turned 23 in 2021 (Chicca \& Shellenbarger, 2018; Mitnick, 2021). Thus, educators must understand Gen Z's unique characteristics if they hope to ensure adequate support of their learning and preparation for careers in the industry.

One cannot speak of Gen $\mathrm{Z}$ without acknowledging the influence of technology and access to information. These digital natives rely on electronics, have lived with the digital ecosystem of internet access, social network sites, or slick multiplatform environments, and received early exposure to web-based tools and learning management systems during their grade school educations (Barreiro \& Bozutti, 2017; Carter, 2018; Chicca \& Shellenbarger, 2018; Francis \& Hoefel, 2018; Mitnick, 2021; Mosca et al., 2019; National Retail Federation, 2019; Nicholas, 2020). Some residual adverse effects associated with this cohort's reliance on technology include underdeveloped social and communication skills, short attention spans, limited quality focus, a desire for quick delivery versus accuracy, and contempt for team-based work, despite valuing social interactions in both face-to-face and online environments (Barreiro \& Bozutti, 2017; Carter, 2018; Chicca \& Shellenbarger, 2018; Kalscheur, 2021; Mitnick, 2021; Mosca et al., 2019; Nicholas, 2020). However, as Meltzer (2017) described, the problem is not the technology itself but the overabundance of information and how to appropriately process or utilize it.

Members of Gen $\mathrm{Z}$ have observed the emotional, physical, financial, and social rollercoasters of other generations and participate in the global COVID-19 pandemic of 2020 -2021(Burke, 2021; Carter, 2018; Chicca \& Shellenbarger, 2018). As a result, they are not risk-takers but cautious sedentary activists who show exceptional levels of resilience and adaptability (Chicca \& Shellenbarger, 2018; Kalscheur, 2021). Many reflect the characteristics of their Generation Xer parents, who are financially conservative (Carter, 2018). Gen $\mathrm{Z}$ members are described as independent, self-reliant, pragmatic, but also altruistic and focused on root causes versus symptoms (Barreiro \& Bozutti, 2017; Carter, 2018; Chicca \& Shellenbarger, 2018; Francis \& Hoefel, 2018; Laura, 2019; Mosca et al., 2019). When faced with issues, they prefer realistic, authentic, but quick solutions. They are known for their abilities to influence their households, having a substantial impact on the family's decision-making and, ultimately, behaviors (National Retail Federation, 2019). Individuals in this population also practice their social views, with strong leanings towards 
environmental sustainability, and will reject activities that do not align with their social consciousness values (Kalscheur, 2021).

Other features of Gen Z include abilities to multitask, exhibiting interest in entrepreneurship, and respect for YouTube and social media influencers as a viable resource for learning, sometimes ranking them ahead of lectures, in-class teamwork, learning applications, and textbooks (Barreiro \& Bozutti, 2017; Carter, 2018; Laura, 2019). Nevertheless, they revere both educators and peers as significant authority figures (National Retail Federation, 2019). Additionally, many Gen Zers work multiple part-time jobs and have difficulty adjusting to workplace or classroom hierarchies. However, they are also more likely to value diversity than previous generations (Barreiro \& Bozutti, 2017; National Retail Federation, 2019).

\section{Gen Z Learning Needs}

As colleges and universities enroll more Gen $\mathrm{Z}$ members into CCMPs and prepare them to enter the workforce, it is critical to assess their unique aspects and requirements (Carter, 2018). Several research studies describe Gen $\mathrm{Z}$ as needing validation, explicit instruction, transparency, and frequent feedback (Barreiro \& Bozutti, 2017; Carter. 2018; Chicca \& Shellenbarger, 2018; Mosca et al., 2019). Moreover, they may lack creativity due to the grade school environment's overly structured nature. They may require scaffolded exposure to challenging assignments that necessitate innovation and written or verbal communication with varying audiences (Carter, 2018; Linder \& Hayes, 2018). As pragmatic individuals, they need to solve real-world problems and be actively engaged in career goals related to hands-on and socially conscious experiences (Barreiro \& Bozutti, 2017; Carter, 2018; Chicca \& Shellenbarger, 2018; Kalscheur, 2021; Mosca et al., 2019).

To address Gen Z learning needs, Nicholas (2020) and Meltzer (2017) suggest adapting the learning environment to include opportunities to interact with real-world clients. Doing so enables the application of theoretical concepts and the building of analytical, creative, and team-building skills or social interactions to reduce the anxiety of working alone. Educators must also actively incorporate technology into the classroom, inform the Gen $\mathrm{Z}$ cohort on its application in the workplace, and explain how to appropriately evaluate and use the plethora of information at our disposal (Carter, 2018; Chicca \& Shellenbarger, 2018; Mosca et al., 2019). Additionally, learning activities that apply innovative technology exploration and community-based service projects can push Gen $\mathrm{Z}$ members out of their comfort zones and prepare them practically for future careers. Further, to develop advanced social skills, collaborative activities and knowledge sharing within the classroom, across disciplines, and blended learning environments are essential for this group of learners (Barreiro \& Bozutti, 2017; Carter, 2018; Chicca \& Shellenbarger, 2018; Mosca et al., 2019). Cumulative extrapolations from literature reviews and nascent experience point to a need for tasks that build students' abilities to self-regulate, persist, and enhance their metacognitive skills. Students may require additional encouragement to take risks and to make mistakes (Nilson, 2013). The curriculum and teaching methods must meet students' needs, monopolize their requirements for new and consistent access to information, and understand that the norm of focused, concentrated attention for long periods is not a part of Gen Z's characteristics yet necessary academic and professional achievement and should therefore be cultivated (Lang, 2020).

\section{DESIRED SKILLS OF EMPLOYERS}

Generally, the National Association of Colleges and Employers (NACE, 2020) career readiness report identifies eight competencies for college graduates critical to successful transitions to the workforce. The competencies include critical thinking and problem-solving; oral and written communications; teamwork and collaboration; use of existing and adaptability to new and emerging technologies; leadership abilities including the leveraging, assessing, and managing the strengths and emotions of self and others; exhibiting professionalism and work ethic built on integrity and personal accountability; managing career goals and opportunities for themselves; and demonstrating global and intercultural respect.

Industries requiring design or creative thinking skills pursue entry-level employees who can quickly adapt to conditions driven by economics. Other noted skills beyond those highlighted by NACE (2020) 
include maturity, neatness in all presentation areas, an aptitude for technical drawing, and general visual communication. However, conceptual and application skills are valued over merely being technicians (Gale, Duffey, Park-Gates, \& Peek, 2017). Other mentioned strengths include congeniality and having a pleasant and energetic attitude. Possessing a disciplined, driven, contributory, and dedicated attitude is necessary for the workplace setting, which requires self and others to manage stressful scenarios.

As of 2020, MOTIF, a social learning platform, identified increased challenges for organizations due to the rapidly changing global environment impacted by COVID-19, sustainability, sourcing, and accelerated innovation. The environment requires a workforce skillful at adjusting to strategic success demands, such as reacting to macro-level business influences. The industry and academics must respond competitively, given rising economic pressures, customer demands and behaviors, and uncertainty. Globally, industry needs are intensified by a dwindling skilled workforce, few recruitment sources, widening skill gaps, and the need to outsource to meet strategic plans. It is essential for those entering the workforce to be able to lead, manage, analyze data, work across team functions, utilize software, develop products, research, design, cultivate new strategies, and be apt in soft skills (selling or negotiation skills, to name a few), well before they leave higher learning institutions.

Thus, to better prepare Gen $Z$ students and address their and industry needs, academics must also equip themselves with teaching and learning strategies that enhance the chances of graduates' success (Gale et al., 2017). The challenges of preparing students for an unknown future require instructional methods beyond technical skills, such as how to think deeply and critically, not only in a traditional classroom but also online, like the current remote professional environments that employ digital modes of operation, including work-related training, team project completion, and other day-to-day tasks. Additionally, it is near impossible to teach students everything they need to know for their future careers. Thus, educators' best options are to motivate students to make learning a continuous priority throughout their lifetimes, focusing on retooling and remaining open to learning, accessing, and utilizing information (MOTIF, 2020).

\section{HIGH IMPACT PRACTICES}

Students' development of employers' desired skills can be accomplished by including HIPs. HIP implementation has increased spurred by the need for innovative and intentional strategies to engage diverse learners (Vaz, 2019). For example, the National Survey of Student Engagement (NSSE; 2020) reports over 1600 higher education institutions since 2000. Kuh (2008) identified HIPs as those teaching and learning activities that enhance student engagement and prospects of individual success and closely align with workforce needs. HIPs, or effective pedagogy, include first-year seminars, common intellectual experiences, learning communities, writing-intensive courses, collaborative assignment and projects, undergraduate research, diversity and global learning, portfolios, service-learning, community-based learning, writing-intensive projects, internships, and CCMPs (Abad-Jorge \& Kronenburg, 2020; Finley, 2019; Kuh, 2008; Linder \& Hayes, 2018). According to the NSSE (2016), similarities across HIPs include an investment of time and effort, learning outside the classroom, meaningful faculty-student and sometimes community interactions, frequent and practical feedback, and diverse collaborative efforts and groups.

Regardless of the modality, HIPs provide several benefits and are described as life transformational. HIPs have also been exhaustively tested and validated as valuable and proven to increase students' cumulative learning by escalating retention rates, timely graduation, success, civic engagement, and positive experiences. HIP experiences also decreased the educational gaps between racial and ethnic groups, especially for the first year, underserved, underrepresented, or socio-economically disadvantaged students (Abad-Jorge \& Kronenburg, 2020; Kinzie, 2012; Linder \& Hayes, 2018). As authentic activities grounded in a real-world application, the very nature of many HIPs enables learners to process, compare, and digest new and complex concepts across disciplines (Nichols Hess \& Greer, 2016). However, to reap the gains fully, these practices require students to engage in at least two HIP acts during their undergraduate years to address the diversity and equity discrepancies. Unfortunately, access to these experiences is not equally available to all students, especially those who have the most to gain from them (Kinzie, 2012; Kuh, 2008; NSSE, 2020). 
Shifts in the educational environment demand recognition of the critical challenges that HIP activities can address between student abilities and workforce needs. The challenges include the increased demand for high-quality degrees and graduates with the ability to think critically, be adaptable, and communicate effectively through various information delivery channels (Linder \& Hayes, 2018). Additionally, student populations are more diverse with varied needs, enhancing accessibility, intentional design, and distance learning requirements while still meeting the expected outcomes. However, research shows that students do not always engage in HIPs, even when offered. For example, Indiana State University's NSSE (2016) data reports that 92 percent of students participated in at least one HIP experience by their senior year. However, only 64 percent completed two or more, and only 40 percent participated specifically in a culminating senior experience.

\section{CAPSTONE COURSES AND MAJOR PROJECTS}

Capstone projects are those climaxing cognitive domain events that draw on students' knowledge acquired throughout their lifetime. When connecting essential learning outcome goals of liberal education, CCMP are categories as practicing integrative and applied learning experiences, similar to learning communities, undergraduate research, service and community-based learning, and internships (Kuh, 2008). The expectation is that students apply their cumulative knowledge to solve a unique or innovative challenge posed by client partners or drawn from industry needs at the highest levels of Bloom's Taxonomy, for example. The project is the course's purpose and encompasses the entirety of a semester or an academic year (Kinzie, 2013). For clarity, CCMPs are not research papers, internships, or service-learning experiences exclusively, although they incorporate each component and objective. While each of the before listed is experiential learning experiences, none are as extensive and rigorous as the intended purpose of CCMPs, which is to integrate the skill-building mechanisms of other HIP practices. CCMPs require students to use and integrate the knowledge gained throughout those and different experiences nearing their final college year to a significant project.

According to Newton-Calvert and Smith Arthur (2018), as a HIP, CCMPs are at the top of the educational milestones journey and are strongly encouraged for all programs. CCMPs inspire students to demonstrate the highest mastery of workforce desired skills. They also require students to grapple with complex material and critical thinking activities independently, in a group context, and collaboratively with the instructor (Linder \& Hayes, 2018). Additionally, these types of courses support students' development and assess their education's cumulative effect (Abad-Jorge \& Kronenburg, 2020; Kinzie, 2013; Kuh, 2008; Linder \& Hayes, 2018; Schermer \& Gray, 2012; Viswanathan, 2017). Students who partook in CCMPs reported increased perceived academic skills and abilities, appreciation for reasoning and achieving, project management skills, and cooperative skills. They also described an enhanced ability to articulate independent thoughts and perform inquiry (Kinzie, 2013; Schermer \& Gray, 2012).

Traditionally used as culminating fourth-year experiences, CCMPs assess programmatic outcomes and students' cumulative learning and knowledge (Kinzie, 2013; Newton-Calvert \& Smith Arthur, 2018). The prevalence and use of capstone courses are more likely in liberal arts, smaller, or private institutions associated with discipline-specific courses (Kinzie, 2013; Newton-Calvert \& Smith Arthur, 2018). With CCMPS, students produce a significant outcome or product while testing their abilities to successfully manage a project that mimics industry professionals' problem-solving and creative thinking challenges. Thus, completed projects entail the creation of new and inventive products from the process of problem examination, information synthesizing (quantitative and qualitative), developing alternative ideas (iteration), creativity, adjusting to ambiguity, evaluating novelty, usefulness, and purposeful esthetics (Im, Hokanson, \& Johnson, 2015). CCMPs provide students with opportunities to grapple with complex, nuanced, and daunting problems. The learning is never complete or finished and occurs in conjunction with the instructor or industry partners. Students report more perceived career readiness gains from their internship and service-learning experiences than CCMPs. However, participants in CCMPs felt better prepared than those who did not participate in any capstone courses, signaling that there are benefits to students' participation (Kinzie, 2013; Kuh, 2008). Some researchers hypothesize that the lack of perceived 
gains may be due to the narrowly focused discipline-specific nature of many CCMPs. In this case, the CCMP design does not intentionally include an interdisciplinary curriculum approach and career readiness, which can enhance the gains from CCMPs.

The Association of American Colleges and Universities (AAC\&U; 2009) Integrative and Applied Learning VALUE Rubric uses the term capstone to indicate the highest level (4) of students' learning. The other levels, refer to increasing students' ability to make connections across the curriculum and cocurricular, include benchmark (Level 1) and milestones (Levels 2 and 3). Learning consists of students' abilities to connect to experiences, link to disciplines, transfer, integrate communication, reflect, and selfanalyze. In Level 4, the capstone, students must show their expanded understanding due to meaningful connections between the formal classroom experiences and the discipline. Secondly, students must have the ability to independently make new connections or draw conclusions from seemingly disconnected pieces of information. Thirdly, they must also adapt and apply methods and perspectives to new conditions. Students should be able to select the most appropriate methods for communicating and integrating data. Lastly, they must demonstrate the ability to reflect on past experiences and evaluate how to best respond to future encounters.

\section{CCMPs as Learning, Assessments, and Job Training Tools}

Higher learning institutions utilize CCMPs across all disciplines to assess and provide evidence of students' learning to differing constituents, including accreditation boards and other governing entities (Kuh, Jankowski, Ikenberry, \& Kinzie, 2014; Newton-Calvert \& Smith Arthur, 2018; Sandeen, 2012). Also, they are strongly associated with career and professional development. However, their original intent was to foster integrative learning (Kinzie, 2013). Thus, considering CCMP strategies to assist students across all learning environments is a must.

More broadly, CCMPs align with best teaching strategies and convert the classroom into an on-the-job simulation by having faculty, students, and industry representatives collaborate as co-investigators (Kinzie, 2013; Linder \& Hayes, 2018; Newton-Calvert \& Smith Arthur, 2018; Schermer \& Gray, 2012). Ideally, this teaching and learning approach should integrate multidisciplinary subjects and teach professional skills and can directly impact the university's industry reputation and ranking. Furthermore, CCMPs that do not incorporate career development, cross-disciplinary perspectives, and reflective practices risk producing limited positive results in students' civic engagement, career orientation, course satisfaction, higher-order thinking, and knowledge application (Kinzie, 2013; Newton-Calvert \& Smith Arthur, 2018; Schermer \& Gray, 2012).

A well-thought-out and designed CCMP can implement many of the tenets of real-world problembased learning (PBL). Specifically, they require students to apply their knowledge by identifying the problem, conducting research, forming goals, thinking independently, solving a problem, evaluating solutions, and documenting and presenting results (Sasipraba et al., 2020). Through the development of these complex problem-solving skills, CCMPs provide students with opportunities to relate their cumulative knowledge and soft skills to their desired profession in preparation for the transition to their career (McNamara et al., 2015). Furthermore, they require appropriate scoping and planning, in addition to corporate client coordinating, buy-in from students, high levels of tolerance for ambiguity and uncertainty, and balanced methods of individuality and group accountability (Viswanathan, 2017). Indeed, these tasks are not outside the scope of the challenges professionals encounter in their daily tasks.

Many of the challenges faced globally by society are new and ever-evolving, requiring academic institutions to move beyond training students to address what is currently known. As described by Jacob (2015) and Kuh (2008), such challenges require inclusive pedagogical research and a broader teaching approach that empowers students through research, application, and skill development. The AAC\&U (2009) Essential Learning Outcomes include "knowledge of human cultures and the physical and natural world," "intellectual and practical skills, personal and social responsibility," and "integrative learning" (Rhodes, 2012, p. 37), all of which are embedded in well-designed CCMPs (Kinzie, 2013). As previously noted, integrative learning was the original goal of CCMPs. AAC\&U (2009) defined integrative and applied learning as "an understanding and a disposition that a student builds across the curriculum and co- 
curriculum, from making simple connections among ideas and experiences to synthesizing and transferring learning to new, complex situations within and beyond the campus," echoing workforce needs (Definition section). However, the lack of integrative learning is an identified flaw of many CCMPs. More specifically, they may not explicitly identify learning outcomes aligned with industry (Kinzie, 2013; Rhodes, 2012).

Figure 1 compares Gen $\mathrm{Z}$ learners and industry needs highlighting the similarities and discrepancies between the cohort's natural inclinations and the workforce's requirements. Table 1 also provides some features of CCMPs and learning aids that can be tapped into and cultivated in Gen Z students. Some recognized characteristics to leverage among Gen Zers include their technology and resource comfort, entrepreneurial spirit, respect, adaptability, and desire for ethical and diverse perspectives (Carter, 2018; Chicca \& Shellenbarger, 2018; Mosca et al., 2019). In contrast, skills to develop in preparation for students' departure from higher education consist of self-management, teamwork appreciation, innovative and critical thinking, and proper understanding and utilization of information and resources. CCMPs offer higher education general education curriculum opportunities to add additional options for providing students with higher HIP learning levels and bridge the gaps between students and their desired professions. However, many students do not access the recommended two years of HIP strategies (NSSE, 2016; NSSE, 2020). Additionally, based on the authors' cumulative experiences, successful implementation of CCMP include features of other HIP activity types such as writing-intensive, collaborative assignments, diversity and global learning, undergraduate research, service learning, internships, and portfolio development.

\section{Project Example - Integrative Cross-Disciplinary}

Suitable design and implementation of CCMPs and HIP strategies require utilizing logic models (Finley, 2019), literature reviews, and the authors' personal experiences. Logic models focus on designing CCMPs by focusing on desired outcomes. Industry needs and the characteristics of Gen Z learners that are not aligned with the industry combine to form the desired results of CCMPs. This section provides an example of a proposed cross-disciplinary integrative CCMP designed for Gen Zers to complete over an entire semester or academic year. The proposed example is designed for a face-to-face course but could be adapted for online environments. Additionally, the capstone project example follows a five-phase process, is intended to occur during one semester, and engages students across three disciplines: communications (COMM), interior architecture design (IAD), and textile apparel and merchandising (TAM). 


\section{FIGURE 1 \\ COMPARISON: GENERATION Z, INDUSTRY NEEDS, AND CAPSTONE COURSES AND MAJOR PROJECTS}

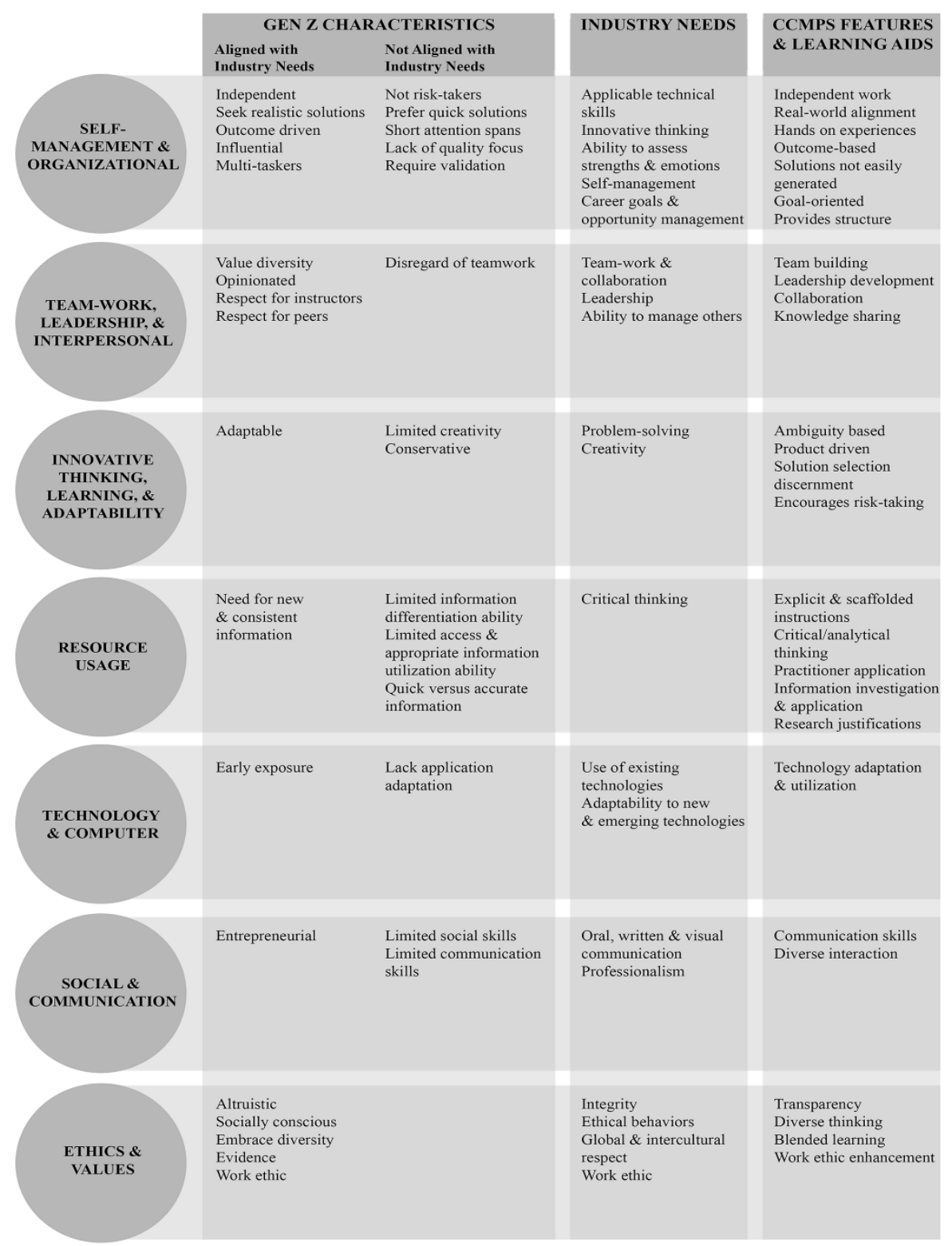

Note: Figure summarizes literature on Gen Z characteristics, workforce needs, and CCMPs' descriptions.

\section{Phase 1 - Outcomes}

Phase 1 focuses on establishing outcomes for the project. This phase should begin at least six months before implementing the project to allow instructors to collaborate, brainstorm, and review best practices, program accreditations, and assessment standards. Outcomes for this project are divided into two categories, overall and major-specific. It is suggested that instructors develop their major-specific objectives aligned with their program, project, assessment, and best practices. Below we share the proposed overall outcomes and their connections with Gen Z:

- Teamwork \& Leadership - Students will collaborate, lead, manage, and work with others as members of cross-disciplinary teams. Gen Zers respect instructors and peers but disregard 
team-based work; industry partners need individuals who work as part of a team, are selfregulating, and goal-oriented (Barreiro \& Bozutti, 2017; NACE, 2020; National Retail Federation, 2019).

- Innovative Thinking - Students integrate multiple levels of information, research, creativity, and exploration to take risks and develop creative solutions to various problems. Gen Zers seek realistic solutions but are not risk-takers and have limited creativity; the industry requests creative, critical thinkers, and problem solvers (Carter, 2018; Chicca \& Shellenbarger, 2018; NACE, 2020).

- Communication - Students demonstrate effective oral, written, and visual communication skills. Gen Z's social and communication skills are underdeveloped; the industry wants strong oral and written communication skills (Barreiro \& Bozutti, 2017; Chicca \& Shellenbarger, 2018; Mosca et al., 2019; NACE, 2020).

- $\quad$ Ethics \& Values - Students make decisions that reflect awareness, consideration, and respect of social, cultural, economic, and international perspectives. Gen $\mathrm{Z}$ values and embraces diversity; industry seeks global and intellectual respect (Chicca \& Shellenbarger, 2018; NACE, 2020).

- Professionalism - Students are respectful, professional, and self-aware and self-assess and focus on business goals and structure. Gen $\mathrm{Z}$ learners are entrepreneurial but prefer quick solutions; the industry wants leaders who display professionalism, including self-management, innovative thinking, and the ability to assess one's strengths and emotions (Carter, 2018; NACE, 2020).

- User-Centered Design - Students value the user and develop solutions that are socially conscious, incorporate emerging technologies and focus on the end-user. Gen $\mathrm{Z}$ focuses on the cause of problems, not just solutions; industry desires individuals who can appropriately use and adapt technology and resources to serve others (Barreiro \& Bozutti, 2017; Carter, 2018; Chicca \& Shellenbarger, 2018; NACE, 2020).

A recommendation is to use a structured rubric to align the stated goals with the assessment criteria and promote consistent grading practices. As an example, the Integrative Cross-Disciplinary Project Rubric (see the Appendix) utilizes all of the suggested overall outcomes identified above. The use of additional majorspecific objectives would warrant a revision to the example Rubric to further align with the intended goals.

\section{Phase 2 - Industry Partners}

The emphasis of phase 2 is on the faculty's identification of industry partners to serve as model clients for the capstone project. The proposed example involves selecting a single industry partner. A single partner is deemed most manageable instead of multiple industry partners - the faculty work with the chosen organization's model clients to identify the problem and set project goals. In addition to the overall outcomes, the project needs to have components focused on applying professional skills, integrative learning, and deep learning specific to each represented discipline (Kinzie, 2013). This proposed capstone project's overall problem should integrate creativity, problem-solving, designing a new space, creating a business plan, and developing a marketing plan.

\section{Phase 3 - Teamwork}

Phase 3 introduces students to the capstone project problem, course outline, process reviews, team structure, and responsibilities. In this phase, lectures based presentations are very unlikely, as the goal is to mimic the workforce. Instead, instructors and partners are encouraged to question students' assumptions and thinking and guide students, but not to provide the answers. Each team should include one student from each discipline, industry partners, and experienced professional mentors. Industry partners serve as model clients. Students will pair with professionals in communications, interior design, and fashion design to serve as mentors and guide them throughout the semester. The teams would be required to have a minimum of five meetings during the semester with mentors and model clients. Students will meet weekly with the 
instructors during the first two months and biweekly during the last two months. The required meetings can occur in a traditional or blended format. Kinzie (2013) notes students report more significant gains and culminating experiences when they interact and receive more feedback from their instructors. Students must provide timelines, team member progress reports, meeting agendas, and minutes for each meeting to model clients, mentors, and instructors. Students, instructors, industry professionals, and mentors must work collectively to enhance student learning and employability (Fedeli \& Vardanega, 2019). Students will present an initial report that includes a preliminary investigation of the problem, schedule, team organization, roles, and responsibilities. Independence is a fundamental goal of the capstone project; therefore, the direction instructors and professionals provide must not limit the students' freedom to define the task and improve their critical thinking and problem-solving skills (Aly, 2016).

\section{Phase 4 - Problem-Solutions}

Phase 4 comprises the bulk of students' problem-solving as they develop an integrated analysis and problem solutions. This phase's overall goal is to solve and evaluate complex, open-ended problems (Meah, Hake, \& Wilkerson, 2020). In response to Gen Zer's desire for transparency and validation, team progress should be monitored through process reviews, meetings, and presentations to faculty and peers. Six process reviews will serve as checkpoints, including rubrics connected to the outcomes, and provide feedback and evaluation of the students' progress throughout the semester (Deepamala \& Shobha, 2018). Teams receive feedback from instructors, mentors, and industry partners after each process review. The process reviews should also correlate with five group presentations. Each group presents their progress and provides feedback by completing group reviews and presenter forms for their peers. The group presentations encourage self-analysis and application of techniques and effective professional communication, focusing on teamwork and communication outcomes. The use of anonymous group reviewer forms is prompted and requires each student to rate the teams' presentation quality and provided overall comments. The group presenter form focuses on listening skills as presenters receive and record the constructive feedback and rate their peers' attentiveness and responsiveness.

\section{Phase 5 - Final}

The final phase includes several forms of project solution documentation and a final presentation to team members, instructors, industry partners, mentors, peers, and community members. Students must develop presentation boards, construction documents, and a cumulative project book that includes all project components and conveys critical thinking, analysis, application, and reflection. Students should apply knowledge and understanding from previous courses in the final project book. The final phase's goal is evidence of the initial outcome and for students to display their knowledge by identifying a problem, forming objectives, conducting research, solving the problem, evaluating, documenting, and presenting their results (Sasipraba et al., 2020).

\section{CONCLUSION}

Appropriately preparing today's students, especially those in underrepresented and underserved groups, to address industry needs requires a collective effort. An effective means of providing students with access to simulated on-the-job training is through HIP strategies, of which CCMPs are a part. Designing and implementing CCMPs that correlate with both Gen $\mathrm{Z}$ and industry needs requires intentionality. Utilizing varying methods and suggestions for planning and executing CCMPs, the authors created a five-phase implementation strategy that purposefully aimed to develop new and enhance prior skills for Gen Z students and to strengthen those that align with industry needs. However, research on the Gen $\mathrm{Z}$ population also

reports a lack of skills desired by those in the field, which general education classrooms can mitigate if students have more access to CCMPs during their undergraduate years. 


\section{REFERENCES}

Abad-Jorge, A., \& Kronenburg, M. (2020). The value of high impact practices and their implementation in an online undergraduate health care management program for adult learners. The Journal of Health Administration Education, 37(1), 355-372. Retrieved from https://www.ingentaconnect.com/content/aupha/jhae/2020/00000037/00000001/art00005

Aly, S. (2016). Bridging the gap between the classroom and real-world through capstone projects. ATEA Journal, 43(2), 30-35. Retrieved from https://www.ateaonline.org/resources/Documents/ATEA\%20Journal_Spring\%202016_v4_FNL.p df\#page $=30$

Association of American Colleges and Universities. (2009). Integrative and applied learning VALUE rubric. Retrieved from https://www.aacu.org/value/rubrics/integrative-learning

Barreiro, S.C., \& Bozutti, D.F. (2017). Challenges and difficulties to teaching engineering to Generation Z: A case research. Propósitos y Representaciones, 5(2), 127-183. doi:10.20511/pyr2017.v5n2.163

Burke, L. (2021, March 3). Campus zero. Inside Higher Ed. Retrieved from https://www.insidehighered.com/news/2021/03/03/first-college-impacted-covid-19-one-year-out

Carter, T. (2018). Preparing Generation Z for the teaching profession. SRATE Journal, 27(1), 1-8. Retrieved from http://www.srate.org/JournalEditions/Volume27-1/Carter_Manuscript.pdf

Chicca, J., \& Shellenbarger, T. (2018). Generation Z: Approaches and teaching-learning practices for nursing professional development practitioners. Journal for Nurses in Professional Development, 34(5), 250-256. doi:10.1097/NND.0000000000000478

Deepamala, N., \& Shobha, G. (2018). Effective approach in making capstone project a holistic learning experience to students of undergraduate computer science engineering program. Journal of Technology and Science Education, 8(4), 420-438. doi:10.3926/jotse.427

Fedeli, M., \& Vardanega, T. (2019). Enhancing active learning and fostering employability: The experience of a two-stage capstone project at the University of Padova. New Directions for Adult and Continuing Education, (163), 25-35. doi:10.1002/ace.20339

Finley, A. (2019, November). A comprehensive approach to assessment of high-impact practices [Occasional Paper]. Association of American College and Universities. Retrieved from https://www.pfw.edu/offices/assessment/resources/pdf/E-HIPSASSESS-8-252020.pdf?language_id=1

Francis, T., \& Hoefel, F. (2018, November 12). 'True Gen': Generation Z and its implications for companies. McKinsey \& Company. Retrieved from https://www.mckinsey.com/industries/consumer-packaged-goods/our-insights/true-gengeneration-z-and-its-implications-for-companies

Gale, A.J., Duffey, M.A., Park-Gates, S., \& Peek, P.F. (2017). Soft skills versus hard skills: Practitioners' perspectives on interior design interns. Journal of Interior Design, 42(4), 45-63. doi:10.1110.1111/joid.12105

Im, H., Hokanson, B., \& Johnson, K.K.P. (2015). Teaching creative thinking skills: A longitudinal study. Clothing and Textiles Research Journal, 33(2), 129-142. doi:10.1177/0887302X15569010

Jacob, W.J. (2015). Interdisciplinary trends in higher education. Palgrave Communications, 1, 1-5. doi:10.1057/palcomms.2015.1

Kalscheur, L. (2021, March 1). How Gen Z and Millennials are influencing the future of shopping. Total Retail. Retrieved from https://www.mytotalretail.com/article/how-gen-z-and-millennials-areinfluencing-the-future-of-shopping/

Kinzie, J. (2012). High-impact practices: Promoting participation for all students. Diversity \& Democracy, 15(3). Retrieved from https://www.aacu.org/publications-research/periodicals/highimpact-practices-promoting-participation-all-students 
Kinzie, J. (2013). Taking stock of capstones and integrative learning. Peer Review, 15(4). Retrieved from https://www.aacu.org/publications-research/periodicals/taking-stock-capstones-and-integrativelearning

Kuh, G.D. (2008). High-impact educational practices. Association of American Colleges \& Universities. Retrieved from https://www.aacu.org/node/4084

Kuh, G.D., Jankowski, N., Ikenberry, S.O., \& Kinzie, J. (2014, January). Knowing what students know and can do: The current state of student learning outcomes assessment in U.S. colleges and universities [Abridged Report]. National Institute for Learning Outcomes Assessment. Retrieved from https://www.luminafoundation.org/wp-content/uploads/2017/08/2013-abridged-surveyreport-final.pdf

Lang, J.M. (2020). Distracted: Why students can't focus and what you can do about it. New York, NY: Basic Books.

Laura, A. (2019, February 15). Higher-ed leaders: Here's how Generation Z learns best. ECampus News. Retrieved from https://www.ecampusnews.com/2019/02/15/higher-ed-leaders-generation-Zlearns-best/

Linder, K.E., \& Hayes, C.M. (Eds.). (2018). High-impact practices in online education: Research and best practices. Sterling, VA; Stylus.

McNamara, J., Field, R., Coe, S., Butler, D., Brown, C., \& Kift, S. (2015). Capstones as transitional experiences. Legal Education Review, 25(1), 7-28. Retrieved from https://www.researchgate.net/publication/301780098_Capstones_as_Transitional_Experiences

Meah, K., Hake, D., \& Wilkerson, S.D. (2020). A multidisciplinary capstone design project to satisfy ABET student outcomes. Education Research International, pp. 1-17. doi: $10.1155 / 2020 / 9563782$

Meltzer, D. (2017, October 4). Combating the millennial attention span to keep your team engaged. Entrepreneur. Retrieved from https://www.entrepreneur.com/article/297833

Mitnick, K. (2021, March 2). 3 brands getting Gen Z marketing right. Total Retail. Retrieved from https://www.mytotalretail.com/article/3-brands-getting-gen-z-marketingright/\#ne=7ea247e886f74eaa66c8a1048eef4fd2\&utm_source=total-retailreport\&utm_medium=newsletter\&utm_campaign $=2021-03-03$

Mosca, J.B., Curtis, K.P., \& Savoth, P.G. (2019). New approaches to learning for Generation Z. Journal of Business Diversity, 19(3), 66-74. doi:10.33423/jbd.v19i3.2214

MOTIF. (2020). The state of skills in the apparel industry: 2020 report. Retrieved from https://motif.org/news/the-state-of-skills-in-the-apparel-industry-2020-report/

National Association of Colleges and Employers. (2020). Career readiness defined. Retrieved from https://www.naceweb.org/career-readiness/competencies/career-readiness-defined/

National Retail Federation. (2019, October 1). Consumer view fall 2019: Keeping up with Gen Z. Retrieved from https://nrf.com/research/consumer-view-fall-2019

National Survey of Student Engagement. (2016). NSSE 16 high-impact practices: Indiana State University. Retrieved from http://irt2.indstate.edu/cms/ir/assets/File/nsse/NSSE16HighImpactPractices.pdf

National Survey of Student Engagement. (2020). High-impact practices: Interrogating quality and equity. Retrieved from https://nsse.indiana.edu/research/annual-results/hips/index.html

Newton-Calvert, Z., \& Smith Arthur, D. (2018). Capstone courses and projects. In K.E. Linder \& C.M. Hayes (Eds.), High-impact practices in online education: Research and best practices (pp. 165181). Sterling, VA: Stylus Publishing.

Nicholas, A.J. (2020). Preferred learning methods of Generation Z.Digital Commons@ Salve Regina. Retrieved from https://digitalcommons.salve.edu/fac_staff_pub/74/

Nichols Hess, A.K., \& Greer, K. (2016). Designing for engagement: Using the ADDIE model to integrate high-impact practices into an online information literacy course. Communications in Information Literacy, 10(2), 264-282. doi:10.15760/comminfolit.2016.10.2.27 
Nilson, L.B. (2013). Creating self-regulated learners: Strategies to strengthen students' self-awareness and learning skills. Sterling, Virginia: Stylus Publishing.

Rhodes, T.L. (2012). Show me the learning: Value, accreditation, and the quality of the degree. Planning for Higher Education, 40(3), 36-42.

Sandeen, C. (2012). High-impact educational practices: What we can learn from the traditional undergraduate setting. Continuing Higher Education Review, 76, 81-89. ERIC. Retrieved from https://files.eric.ed.gov/fulltext/EJ1000654.pdf

Sasipraba, T., Bantha Navas, R.K., Nandhitha, N.M., Prakash, S., Jayaprabakar, J., Pushpakala, S.P., . . . Arunkumar, G. (2020). Assessment tools and rubrics for evaluating the capstone projects in outcome based education. Procedia Computer Science, 172, 296-301. doi:10.1016/j.procs.2020.05.047

Schermer, T., \& Gray, S. (2012). The senior capstone: Transformation experiences in the liberal arts. Retrieved from http://www.teaglefoundation.org/Teagle/media/GlobalMediaLibrary/documents/resources/The_S enior_Capstone.pdf?ext=.pdf

Viswanathan, S. (2017). Implementation of effective capstone projects in undergraduate manufacturing design engineering program. American Journal of Engineering Education, 8(1), 45-60. doi:10.19030/ajee.v8i1.9967

\section{APPENDIX: INTEGRATIVE CROSS-DISCIPLINARY PROJECT RUBRIC}

Teamwork and Leadership

Effectively collaborate, lead, manage, and work with others as members of cross-disciplinary teams.

$\begin{array}{lllllll}\text { Mastery } & 10 & 8.5 & 7.5 & 6.5 & 0 & \text { Not Yet }\end{array}$

\section{Innovative Thinking}

Meaningfully integrate multiple levels of information, research, creativity, and exploration to take appropriate risks and develop creative solutions to various problems.
Mastery
108
7.5
6.50
Not Yet

\section{Communication}

Demonstrate effective oral, written, and visual communication skills.

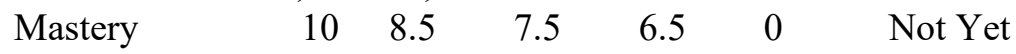

\section{Ethics \& Values}

Make intentional decisions that reflect awareness, consideration, and respect of cultural, economic, and international perspectives.

$$
\begin{array}{lllllll}
\text { Mastery } & 10 & 8.5 & 7.5 & 6.5 & 0 & \text { Not Yet }
\end{array}
$$

\section{Professionalism}

Demonstrate respect, professionalism, and self-awareness, and self-assess and focus outcomes on business goals and structure.

$\begin{array}{lllllll}\text { Mastery } & 10 & 8.5 & 7.5 & 6.5 & 0 & \text { Not Yet }\end{array}$

\section{User-Centered Design}

Value the user and develop socially conscious solutions, incorporate emerging technologies, and focus on the end-user.

$\begin{array}{lllllll}\text { Mastery } & 10 & 8.5 & 7.5 & 6.5 & 0 & \text { Not Yet }\end{array}$

